\title{
Comparative Neurobiology of Feeding in the Opisthobranch Sea Slug, Aplysia, and the Pulmonate Snail, Helisoma: Evolutionary Considerations
}

\author{
Margaret M. Wentzell ${ }^{\mathrm{a}}$ Clarissa Martínez-Rubio ${ }^{\mathrm{b}}$ Mark W. Miller ${ }^{\mathrm{b}}$
}

A. Don Murphy ${ }^{a}$

a Department of Biological Sciences and Laboratory of Integrated Neuroscience, University of Illinois

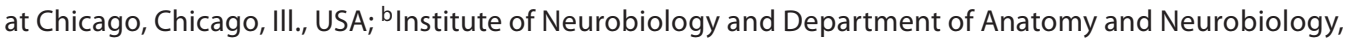
University of Puerto Rico Medical Sciences Campus, San Juan, Puerto Rico

\section{Key Words}

Central pattern generator - Octopamine $\cdot$ Swallowing • Small cardioactive peptide $\cdot$ Buccal ganglion $\cdot$ Gastropod Mollusk

\begin{abstract}
The motor systems that generate feeding-related behaviors of gastropod mollusks provide exceptional opportunities for increasing our understanding of neural homologies and the evolution of neural networks. This report examines the neural control of feeding in Helisoma trivolvis, a pulmonate snail that ingests food by rasping or scraping material from the substrate, and Aplysia californica, an opisthobranch sea slug that feeds by using a grasping or seizing motion. Two classes of neurons that are present in the buccal ganglia of both species are considered: (1) clusters of peptidergic mechanoafferent cells that transmit sensory information from the tongue-like radula/odontophore complex to the central motor circuit; and (2) sets of octopamine-immunoreactive interneurons that are intrinsic to the feeding network. We review evidence that suggests homology of these cell types and propose that their roles have been largely conserved in the control of food-scraping and food-grasping consummatory behaviors. We also consider significant differences in the feeding systems of Aplysia and Helisoma that are associated
\end{abstract}

with the existence of radular closure in Aplysia, an action that does not occur in Helisoma. It is hypothesized that a major adaptation in the innervation patterns of analogous, possibly homologous muscles could distinguish the food-scraping versus food-grasping species. It appears that although core CPG elements have been largely conserved in this system, the neuromuscular elements that they regulate have been more evolutionarily labile.

Copyright $\odot 2009$ S. Karger AG, Base

'The natural emphasis on discovering commonalities, homologies and analogies that simplify has distracted us from the main result of evolution, which is to create differences.'

T.H. Bullock, 2002

\section{Introduction}

Half a century ago, the recognition of species-specific behaviors contributed to a conceptual convergence between the disciplines of ethology and comparative psychology [Lorenz, 1950; Schneirla, 1952; Dethier and Stellar, 1961; Mason and Lott, 1976]. The subsequent emergence of neuroethology produced an understanding of several species-specific actions at the level of their under-

\section{KARGER}

() 2009 S. Karger AG, Basel

Fax +4161306 1234

E-Mail karger@karger.ch

www.karger.com
Accessible online at: www.karger.com/bbe
Dr. A. Don Murphy

Department of Biological Sciences, University of Illinois at Chicago MIC 067, 840 W. Taylor, Chicago, IL 60607 (USA)

Tel. +1 312996 8087, Fax +1 312996 2805, E-Mail dmurphy@ uic.edu 


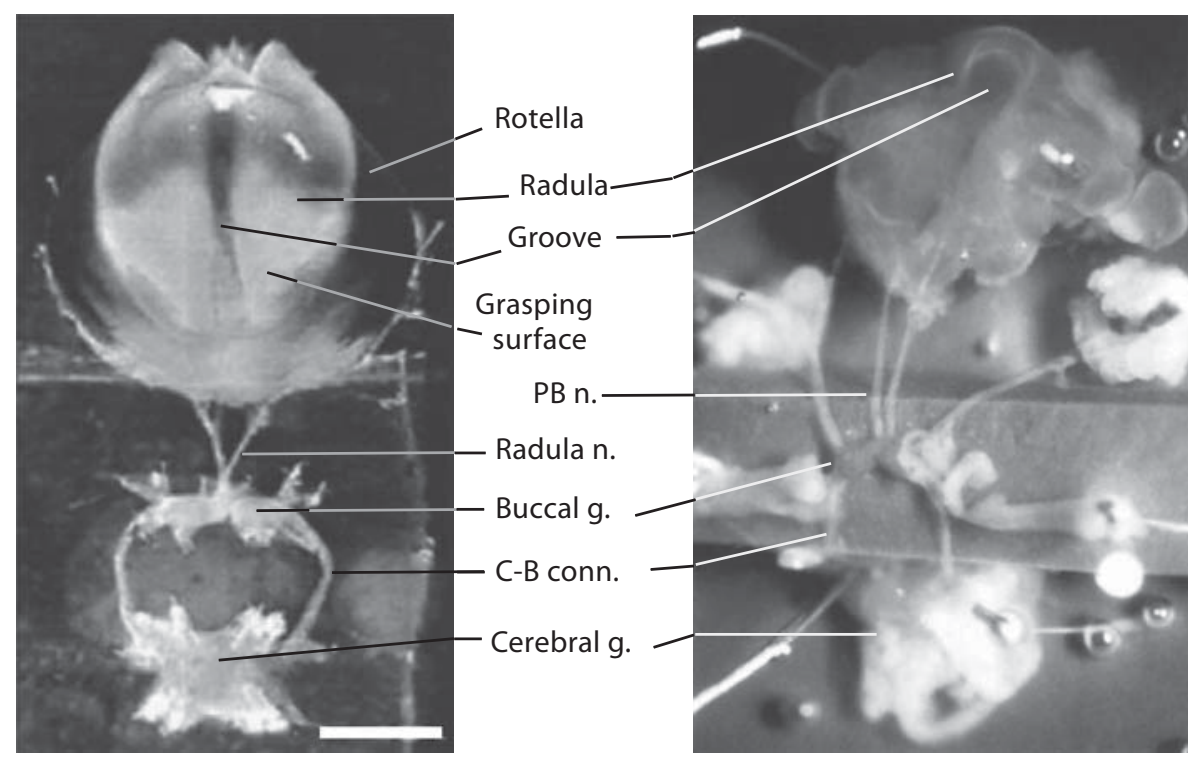

Fig. 1. Comparative anatomy of Aplysia and Helisoma feeding systems. Left panel: the isolated odontophore-CNS preparation of Aplysia californica [modified from Rosen et al., 2000a]. This preparation includes the radula with its support structures (e.g. the rotella) and the innervation from the buccal ganglion (buccal g.) and cerebral ganglion (cerebral g.) via the radula nerve (radula n.) as well as the cerebral-buccal connective (C-B conn.). The external (dorsal) surface of the radula is viewed from above (anterior toward the top, posterior toward the bottom). This orientation corresponds to the resting position of a non-feeding specimen. During a bite, the odontophore is rotated in the anterior direction, bringing the grasping surface into contact with the potential food. During this phase of radula protraction, the two radula halves become closed around the medial longitudinal groove, serving to grasp the food prior to its subsequent retraction and backward rotation, transporting the food into the oral cavity. Right panel: A similar view of odontophore-CNS preparation of Helisoma trivolvis. Note that the lip of the odontophore at the anterior end of the radular groove is relatively broader than that of Aplysia. The odontophore of Helisoma is used as a scoop and the lateral walls do not close. The posterior buccal nerves (PB n.) of Helisoma correspond to the radula nerve of Aplysia. lying neural circuits [Willows and Hoyle, 1967; Camhi, 1984; Kandel, 1975, 1979]. Some of these circuits were comprised of 'identified neurons' that were readily observed in all members of a particular species [Wiersma, 1952; Bullock and Horridge, 1965]. Comparisons of extant species led to the identification of homologous neurons [Sakharov, 1976; Weiss and Kupfermann, 1976; Granzow and Rowell, 1981; Pentreath et al., 1982; Croll, 1987], providing opportunities to perform comparative studies that could disclose general principles of nervous system adaptation and evolution [Arbas et al., 1991; Katz, 1991; Paul, 1991; Katz and Harris-Warrick, 1999].

The motor systems that generate feeding-related behaviors of gastropod mollusks provide fertile terrain for expanding our understanding of neural homologies and the evolution of neural networks [Benjamin, 1983; Bulloch and Ridgeway, 1995; Murphy, 2001; Elliott and Susswein, 2002]. Importantly, the motor patterns that these circuits generate can be directly related to parameters of feeding actions that are likely to reflect adaptations to evolution- ary pressures. The adaptive radiation of the class Gastropoda produced a remarkable variety of feeding strategies and structures [Kohn, 1983; Audesirk and Audesirk, 1985; Chase, 2002]. For example, in Conus detachable radular teeth can be used as harpoons to inject toxins [Duda et al., 2001], whereas in Navanax the radula is lost, and ingestion occurs by suction arising from rapid enlargement of the buccal mass [Susswein et al., 1987]. Here, we examine two examples of gastropods that employ a grazing consummatory strategy consisting of cyclic repetitions of three basic movements: protraction, retraction, and hyperretraction of a radula/odontophore complex. In the pulmonate snail, Helisoma trivolvis and the opisthobranch sea slug, Aplysia californica as well as related animals, this structure is a chitinous tooth-covered radula attached to a tongue-like cartilaginous odontophore (fig. 1). Although its action during ingestion in Helisoma resembles a rasping or scooping movement that scrapes food from the substrate, the ingestive behavior that has been most extensively examined in Aplysia cor- 
responds to the grasping or biting movements that are performed to consume a strip of seaweed [see Kupfermann, 1974a, b].

This report considers two sets of neurons that were originally characterized using immunohistochemical studies aimed toward localizing specific neuromodulators in the Helisoma and Aplysia feeding systems. The neurons to be examined include (1) a cluster of cells on the rostral surface of the buccal ganglia that exhibits immunoreactivity to antibodies raised against the molluscan small cardioactive peptide $\mathrm{B}\left(\mathrm{SCP}_{\mathrm{B}}\right)$ [see Lloyd et al., 1987; Masinovsky, et al., 1988]; and (2) a set of octopamine immunoreactive neurons on the caudal surface of the buccal ganglia. We review evidence that suggests homology of these cell types and propose that their roles have been largely conserved in the context of a fundamental tripartite CPG that controls radula/odontophore protraction, retraction and hyperretraction [Murphy, 2001]. In contrast, major differences in the feeding systems of Aplysia and Helisoma are attributed to the existence of radular closure in Aplysia and the plasticity of its occurrence with respect to the core tripartite protraction-retraction-hyperretraction feeding cycle. Such closure movements do not occur in Helisoma. One consequence of this adaptation might involve modifications in the innervation patterns of analogous, possibly homologous muscles.

\section{The Radula/Odontophore Complex of Aplysia and Helisoma: A Structural and Functional Comparison}

A comparison of the central neural circuits that control consummatory behaviors of Aplysia and Helisoma can best be appreciated in the context of the peripheral structures that execute these actions. The neuromuscular systems mediating feeding in Aplysia and Helisoma are remarkably similar with some notable differences. A direct comparison might be accomplished in partially dissected pharyngeal muscular buccal masses of the two species (fig. 1). In these preparations, anterior dorsal slits were made to divide the muscles forming the dorsal walls of the buccal masses. The cut muscles were pinned laterally to expose the dentated radulae covering the odontophoral 'cartilages' (complex tissue that is not true cartilage).

The odontophores of Aplysia and Helisoma both have a pronounced concavity in the dorsal aspect forming a radular groove; however the radulae of the two gastropods function differently during their typical feeding modes. Aplysia generally feeds on stem-like seaweed that it grasps

Comparative Neurobiology of Gastropod Feeding with its radula and pulls into the oral cavity [Kupfermann, 1974a]. During Aplysia feeding, the radula is protracted in the open configuration. The lateral walls of the radular groove are then closed in apposition to each other, thereby grasping the seaweed. The radula halves remain closed throughout retraction, moving the food into the oral cavity. During egestive movements, the radula is closed during protraction and opened prior to retraction, thus moving material toward the exterior. By contrast, in Helisoma closure of the walls lining the radular groove does not occur during ingestive or egestive actions. Rather, Helisoma uses the odontophore as a scoop with the file-like radula being retracted over the lip of the odontophoral scoop, rasping microscopic algae from the substrate. The scoop is broadest during protraction and becomes progressively narrower through retraction and hyperretraction, but the walls of the scoop never become apposed to each other. In addition, Helisoma can also sweep the lip of the odontophore past the dorsal mandible in a scissoring movement to cut off pieces of macrophytes.

The functional differences between the radula/odontophore systems of Aplysia and Helisoma are reflected by their neuromuscular control. Radular closure in Aplysia is accomplished primarily by muscles I4 and I6. I4 appears to be analogous to the supralateral radular tensor (slrt) muscle of basommatophoran snails. The slrt muscle helps to retract and hyperretract the odontophore and to retract and tense the radula. The innervation of these muscles in the two gastropods is quite different. The I4 closure muscle of Aplysia receives major innervation from a pair of motor neurons, B8a and B8b, with axons in the radula nerve, equivalent to the pair of posterior buccal nerves of Helisoma [Morton and Chiel, 1993b; Church and Lloyd, 1994]. In Helisoma the slrt is controlled by a set of retraction phase and hyperretraction phase motor neurons including B110 [Zoran et al., 1989; Szabo, 2001] and B18 and B19 [Kater, 1974; Arnett, 1996]. These neurons all have axons in the ventrobuccal nerves equivalent to the buccal nerve 3 (Bn3) of Aplysia. Neurons corresponding to the $\mathrm{B} 8 \mathrm{a}$ and $\mathrm{B} 8 \mathrm{~b}$ radula closure motor neurons of Aplysia do not appear to be present in Helisoma.

\section{Radula Mechanoafferent Neurons in Aplysia and Helisoma}

Radula Mechanoafferent Cells of Aplysia californica Immunohistochemical studies using a polyclonal antibody generated against the molluscan $\mathrm{SCP}_{\mathrm{B}}$ identified a 
cluster of approximately 40 apposed cell bodies on the rostral surface of each buccal hemiganglion (fig. $2 \mathrm{~A}_{1}$ ) [Miller et al., 1994; see also Lloyd et al., 1987]. Although the neurons comprising this group exhibited heterogeneity of size and shape, dye injections showed that they all projected an axon to the radula nerve. These fibers innervated the subradula tissue (srt), a thin muscular sheet lining the internal surface of the food-grasping radula. Several observations indicated that these neurons transduce tactile stimuli applied to the radula surface: (1) each cell responded to the touch of a circumscribed receptive field with a rapidly adapting burst of action potentials (fig. $2 \mathrm{~A}_{2}$ ); (2) the evoked spikes generally arose abruptly from the resting potential without prepotentials; and (3) the responses persisted when central and peripheral synaptic transmission was blocked in high $\mathrm{Mg}^{2+}$, low $\mathrm{Ca}^{2+}$ artificial seawater solutions. Based upon these observations, the rostral clusters of $\mathrm{SCP}_{\mathrm{B}}$-immunoreactive neurons were designated radula mechanoafferents (RM) [Miller et al., 1994].

To date, two of the RM neurons (designated B21 and B22) have been individually identified based upon their size, shape, position, and synaptic connectivity [Cropper et al., 1996; Rosen et al., 2000a, b]. The presence of these large identified mechanosensory cell bodies within the buccal ganglion has enabled investigators to explore a spectrum of questions concerning sensorimotor integration in the context of the feeding CPG [Cropper et al., 1996; Alexeeva et al., 1998; Borovikov et al., 2000; Evans et al., 2003a, b, 2005, 2007, 2008]. Initially, B21 was observed to receive excitatory synaptic input during the retraction phase of fictive buccal motor programs (BMPs) (fig. $2 \mathrm{~A}_{3}$ ), suggesting that this cell was influenced by the buccal CPG, and not simply responding to peripheral tactile stimuli [Rosen et al., 2000a; see also Miller et al., 1994]. Furthermore, the RMs sometimes fired only during late retraction or possibly during hyperretraction (compare fig. $2 \mathrm{~A}_{3}$ with fig. $3 \mathrm{~A}$ ). $\mathrm{B} 21$ was also found to exert extensive chemical and electrical synaptic actions on buccal motor neurons and interneurons [Rosen et al., 2000a], including rapid EPSPs that were shown to be mediated by glutamate [Klein et al., 2000]. Collectively, these observations led to the proposal that B21 could participate in generating the phase transition from radula protraction to retraction or in switching from biting to swallowing [Borovikov et al., 2000; Rosen et al., 2000a].

A more complex role for B21 was suggested when it was shown to act as a proprioceptor in addition to its previously described exteroceptive function [Cropper et al., 1996; Borovikov et al., 2000]. When motor programs were elicited in a semi-intact buccal system in which the srt retained its innervation, srt contractions and centripetal B21 impulses occurred during the BMP protraction phase [Borovikov et al., 2000]. Interestingly, impulses generated during protraction might not generate synaptic responses in many of the postsynaptic targets of B21, as the centrally derived somatic depolarization that occurs during retraction can act in a permissive fashion to gate impulse conduction through its inexcitable cell body [Evans et al., 2003a, b, 2005, 2007, 2008]. Finally, injection of depolarizing current into a single B21 to increase firing during the retraction phase of ingestive BMPs produced a significant prolongation of fictive retraction [ShetreatKlein and Cropper, 2004]. Together, the response properties, synaptic connections, firing patterns, and central gating of B21 activity led to the proposal that it can contribute to prolonging the closure/retraction phase of BMPs when the radula grasps food, and that this augmented BMP retraction phase could contribute to the hyperretraction of the radula that occurs during swallowing (see Discussion) [Cropper et al., 2004; Shetreat-Klein and Cropper, 2004].

\section{Radula Mechanoafferent Cells of Helisoma trivolvis}

The rostral cluster of small cardioactive peptide B-like immunoreactive (SCP-li) neurons in the (termed the B101 cluster) buccal ganglion of Helisoma was initially described in the mid-1980s [Murphy et al., 1985; Lukowiak and Murphy, 1987], using a monoclonal antibody (provided by A.O.D. Willows, S. Kempf, and B. Masinovsky). The cluster was always composed of four larger neurons and at least five smaller cells (fig. $2 \mathrm{~B}_{1}$ ). The four largest neurons in the cluster are called B101-B104 (formerly VB1-VB4) [Murphy, 2001]. Neurons B101-B104 each project axons to both posterior buccal nerves [Lukowiak and Murphy, 1987]. Neurons B101 and B102 are the two largest members of the cluster, with the soma of B101 being more laterally positioned than that of neuron B102. Recently, the B101 cluster became a focus of the Ph.D. thesis of M. Delfeld (now Wentzell) [2008] who examined the presence or absence of homology between these neurons and the SCP-li RMs of Aplysia. The Helisoma neuron $\mathrm{B} 101$ cluster also proved to be RMs, responding to light touch of the radula surface (fig. $2 \mathrm{~B}_{2}$ ). Such stimuli triggered depolarizations that sometimes exceeded the threshold for action potentials in the neuron B101 cluster neurons (fig. $2 \mathrm{~B}_{2}$ ). The most striking physiological characteristic of the neurons in the B101 cluster was their 'influential' capacity [terminology of Arshavsky et al., 1988] in the control of phase 3 (odontophore hyperretraction). 

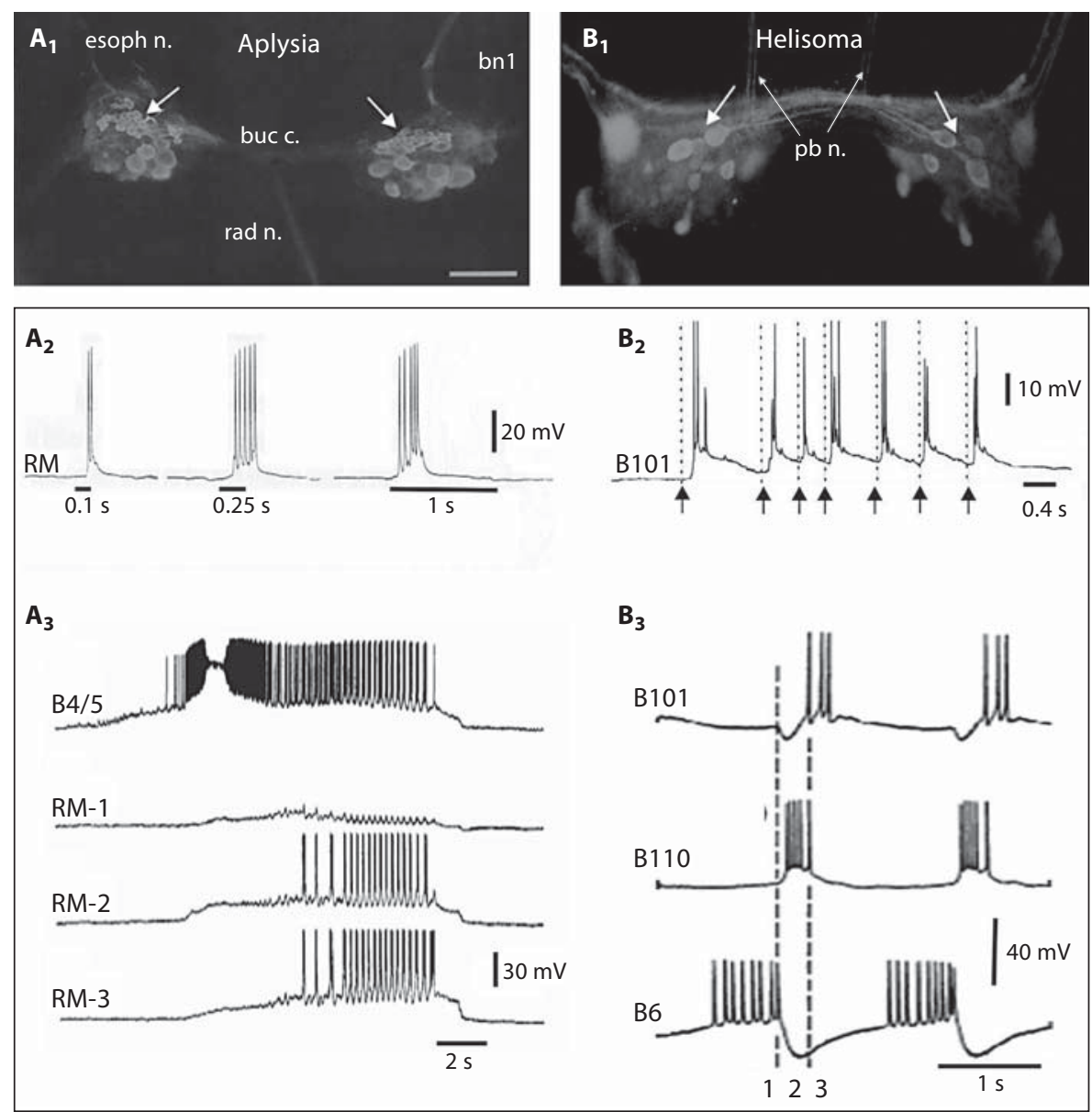

Fig. 2. RM neurons in Aplysia and Helisoma. $\mathbf{A}_{\mathbf{1}}$ SCP-like immunoreactive (SCP-li) neurons on the rostral surface of the Aplysia californica buccal ganglia [modified from Miller et al., 1994]. A cluster of closely apposed medium-sized (20-80 $\mu \mathrm{m})$ sensory neurons was located in the central region of each hemiganglion (arrows). The larger cell bodies located more ventrally are motor neurons that also contain the small cardioactive peptides $\mathrm{A}$ and B [see Church and Lloyd, 1991]. A 2 Intracellular recording from one of the neurons in the RM cell cluster [modified from Miller et al., 1994]. Responses to a $1 \mathrm{~g}$ von-Frey-hair applied to the radula surface for progressively increasing durations (stimuli indicated by the horizontal bars). Impulses were not preceded by synaptic activity. Note that the response to the longest stimulus (1 s) exhibited rapid adaptation. $\mathbf{A}_{\mathbf{3}}$ Activity in three RM neurons (RM-1, RM-2, and RM-3) during a spontaneous buccal motor program. Importantly, this recording was obtained from a preparation in which the buccal ganglion remained attached to the radula/odontophore (see fig. 1A) [modified from Miller et al., 1994]. Recording from the multifunctional neuron B4/5 was used as a reference for determining the phase of activity of the RM neuron. The RM neurons depolarized and some fired repetitive brief bursts during the late phase of $\mathrm{B} 4$ firing. $\mathbf{B}_{\mathbf{1}}$ SCP-li neurons viewed from the rostral surfaces of the buccal ganglia of Helisoma tri- volvis. Arrows point to the mechanoafferent neuron cluster. Some caudal somata, for example the lateral giant salivary neurons, showed through the ganglia. $\mathbf{B}_{\mathbf{2}}$ Mechanical stimulation of the radula of a semi-intact Helisoma preparation while recording from mechanoafferent neuron B101. A fine wire was mounted in a micromanipulator and mechanically apposed to the surface at the arrows. $\mathbf{B}_{\mathbf{3}}$ Simultaneous intracellular recordings from protraction phase motor neuron $\mathrm{B} 6$, retraction phase motor neuron B110, and hyperretraction phase SCP-li radular mechanoafferent $\mathrm{B} 101$, during a fictive feeding motor pattern. bn $1=$ Buccal nerve 1; buc c. = buccal commissure; $\mathrm{pb} \mathrm{n}$. = posterior buccal nerve; $\mathrm{rad}$ n. = radular nerve; $\mathrm{RM}=$ radular mechanoafferent. At the time they were identified, the rostral buccal ganglia surfaces of basommatophoran snails were referred to as 'ventral' and the caudal surfaces were termed 'dorsal' [e.g. Kater, 1974; Rose and Benjamin, 1981], thus the four larger SCP-li neurons were labeled VB1VB4 [Murphy, 2001]. The buccal ganglia surface designations were subsequently changed to the more anatomically precise 'rostral' and 'caudal' and the ' $V$ ' was dropped from the labels of neurons on the rostral surfaces, with the number ' 1 ' substituted. Hence, neurons VB1-VB4 became neurons B101-B104 [Murphy, 2001]. 

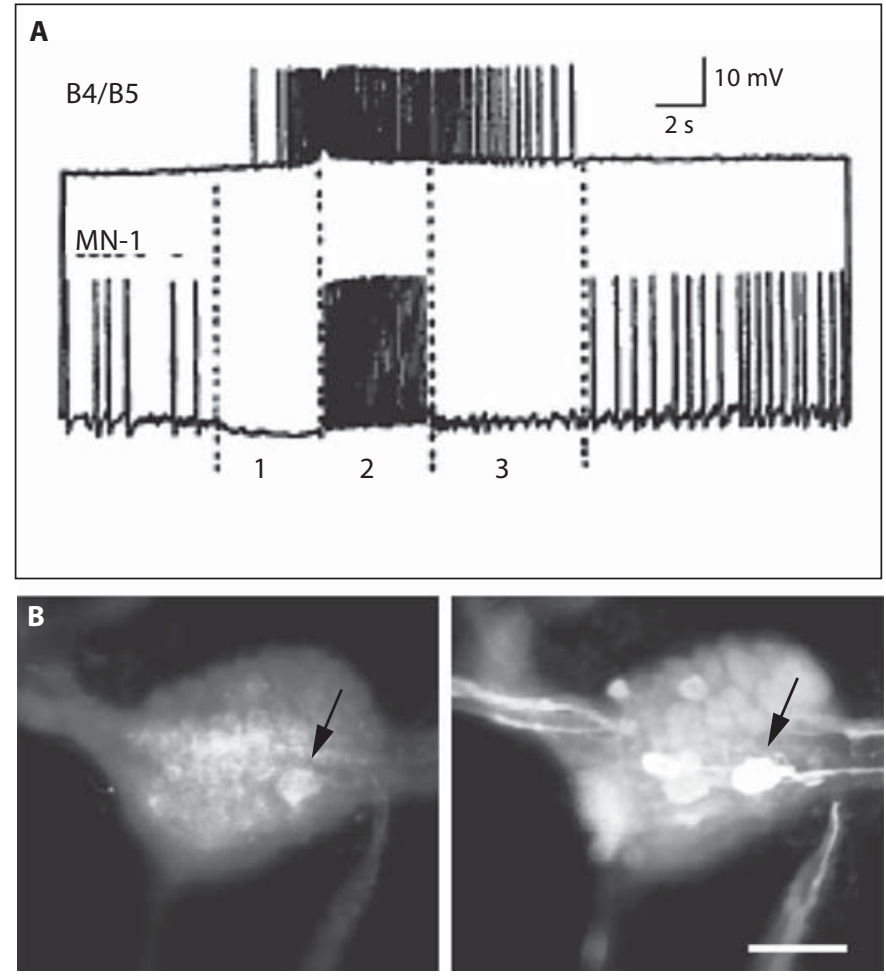

Fig. 3. Further evidence for homology of Aplysia and Helisoma RMs. A Simultaneous intracellular recordings from Aplysia neuron B4/B5 and an unidentified presumptive motor neuron. The motor neuron appears to be inhibited during phase 3 of the motor pattern. The activity in neuron B4/B5 would have suggested that this was late retraction but we are proposing that it should be considered phase 3 , hyperretraction. A comparison with figure $2 \mathrm{~A}_{3}$ then suggests that the RM neurons were also firing during phase 3, hyperretraction. B Double immunocytochemical staining of Helisoma's left buccal ganglion with antibodies to glutamate and $\mathrm{SCP}_{\mathrm{B}}$. The ganglion is viewed from the rostral surface, with the commissure to the right, $\mathrm{Cb}$ c.: upper left, ET: lower left. Left panel: glutamate-like immunoreactivity in the soma of neuron B102 (arrow). Right panel: SCP-li was also seen in the soma of B102. $\mathrm{Cb} \mathrm{c}=$ Cerebral-buccal connective; ET = esophageal trunk. Scale bar: $100 \mu \mathrm{m}$. Figure 3A is modified from Murphy [2001] and figure $3 \mathrm{~B}$ is modified from Delfeld [2008].

In addition to firing during phase 3 of the triphasic feeding motor pattern (fig. $2 \mathrm{~B}_{3}$ ), these neurons could evoke phase 3-like PSPs in motor neurons when depolarized [cf. figs. 7 and 8 in Lukowiak and Murphy, 1987]. In addition, hyperpolarization of B101 cluster neurons during ongoing buccal motor patterns eliminated phase 3 PSPs.

Further support for homology between the B101 neurons and the RM cells was obtained in exploratory experiments conducted on Aplysia, in which the activity of some motor neurons suggested that its phase of radula retraction could be partitioned into two subphases, that is retraction and hyperretraction [fig. 3A; see also Jing et al., 2004; and Discussion]. Finally, dual immunocytochemical experiments [Delfeld, 2008] showed that Helisoma neuron B102 stained for both glutamate and SCP (fig. 3B), further suggesting homology with Aplysia neuron B21. Delfeld [2008] also showed that the Helisoma mechanoafferents evoked widespread PSPs in neurons that were not active during phase 3 in addition to those active during phase 3. The presence and amplitude of these PSPs were a function of the timing of stimulation of the RMs within a feeding cycle, as demonstrated in the B21 neuron of Aplysia [cf. Evans et al., 2003b, 2007, 2008].

\section{Octopamine-Like Immunoreactive Interneurons}

The second set of neurons to be addressed consists of three octopamine-like immunoreactive (OA-li) neurons on the caudal surface near the buccal commissure: one bilateral pair of neurons and one unpaired neuron (fig. 4).

\section{Octopamine-Like Immunoreactive Buccal \\ Interneurons in Aplysia}

A recent report described three moderately sized $(\sim 80$ $\mu \mathrm{m}$ diameter) OA-li neurons in the paired buccal ganglia of A. californica [Martínez-Rubio et al., 2008]. An additional investigation demonstrated a pattern of OA-li in the buccal ganglion of Aplysia dactylomela (subgenus Varria) that was indistinguishable from that observed in A. californica (fig. $4 \mathrm{~A}_{1-3}$ ). In both Aplysia species, two of the three OA-li somata were located in bilaterally symmetric positions in the medial region near the caudal surface of each hemiganglion. The third OA-li buccal neuron was usually located within the buccal commissure that joins the two hemiganglia. There was some variation in the precise position of this third cell, which tended to be skewed toward the left hemiganglion. In no instance was a contralateral counterpart detected. Although the immunolabeling did not permit extensive tracing of the projections from the three buccal OA-li neurons, it was usually possible to detect a stout axon hillock from each of the bilateral paired cells oriented toward the buccal commissure (fig. $4 \mathrm{~A}_{2}$ ). The unpaired cell had a bipolar profile, with major projections originating from its soma projecting toward the neuropil regions of each buccal hemiganglion. No OA-li fibers were observed in any of the buccal nerves or on peripheral tissues associated with the buccal ganglion, e.g. buccal muscles, pharynx, and 

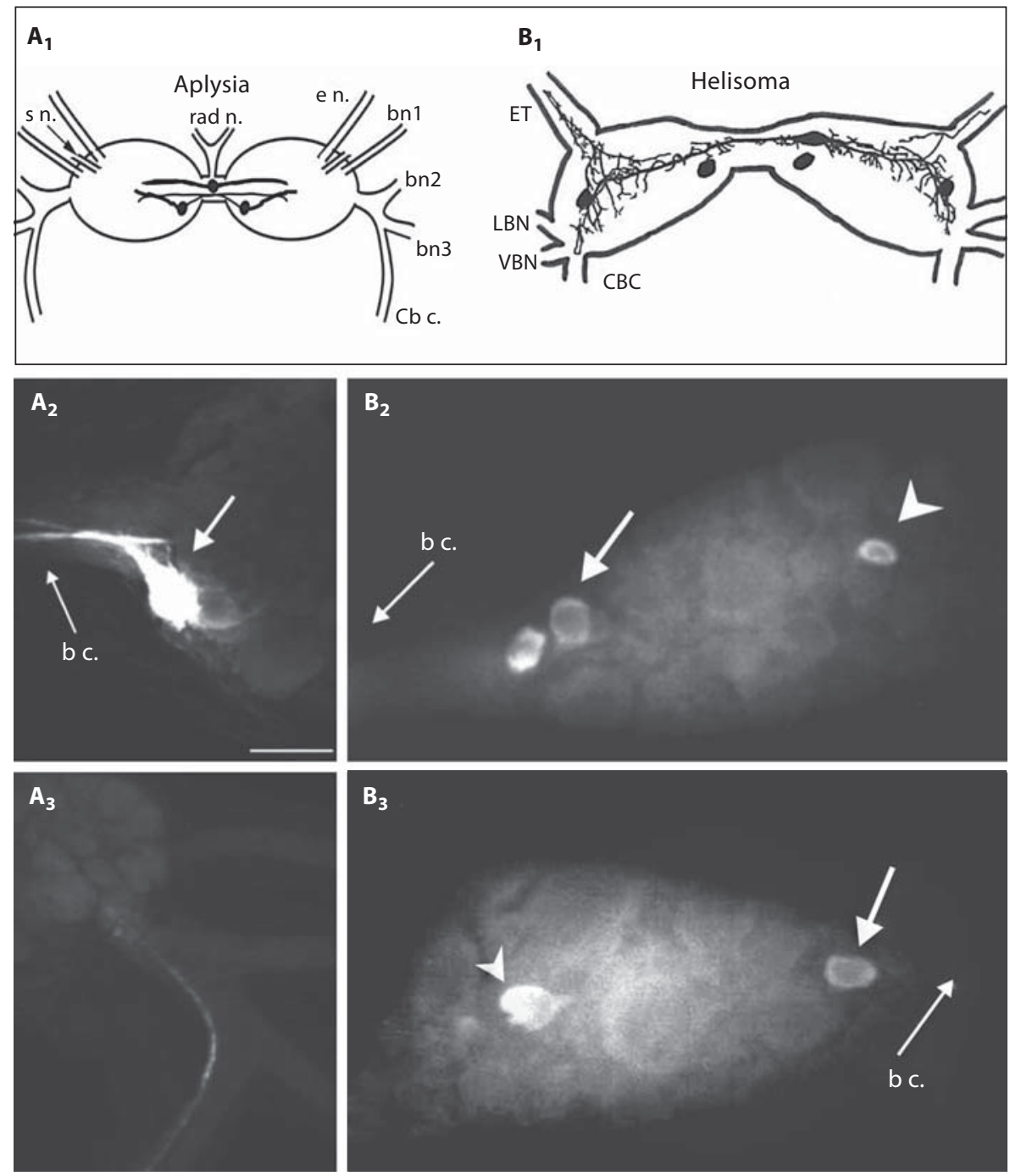

Fig. 4. Octopamine-like immunoreactivity (OA-li) in the buccal ganglia of Aplysia and Helisoma. $\mathbf{A}_{\mathbf{1}}$ Schematic representation of OA-li in the paired buccal ganglion of Aplysia. Results of experiments performed on two species, Aplysia californica and Aplysia dactylomela (shown here) were indistinguishable. Strong OA-li was limited to three moderately sized neurons near the caudal surface. $\mathbf{A}_{\mathbf{2}}$ Two of the OA-li neurons were positioned symmetrically in the medial region of each hemiganglion (right hemiganglion shown here). These cells gave rise to fibers that traversed the buccal commissure connecting the two hemiganglia. $\mathbf{A}_{\mathbf{3}} \mathrm{A}$ single OA-li fiber in the cerebral-buccal connective ( $\mathrm{Cb}$ c.). $\mathbf{B}_{\mathbf{1}}$ Schematic representation of OA-li somata on the caudal surface of the Helisoma buccal ganglia. A tracing of the neuritic processes of a Lucifer yellow-stained neuron N3a was superimposed onto the upper OA-li soma. $\mathbf{B}_{\mathbf{2}}$ Photograph of OA-li on the caudal surface of the right buccal ganglion of Helisoma trivolvis. ET is to upper right, $\mathrm{Cb}$ c. to lower right. Two N3A neuronal somata (arrow) are seen next to the commissure, and one unidentified OA-li soma (arrowhead) is seen in the lateral part of the ganglion. $\mathbf{B}_{\mathbf{3}}$ In the left buccal ganglion one N3a (arrow) was stained near the buccal commissure and one unidentified lateral cell (arrowhead) was stained. The location of the unpaired N3a somata is variable and can be in either the left or right buccal ganglion. s n. = Salivary nerve; e n. = esophageal nerve; $\mathrm{ET}$ = esophageal trunk; bn 1 = buccal nerve 1 ; bn 2 = buccal nerve 2 ; bn $3=$ buccal nerve 3 ; $\mathrm{Cb} \mathrm{c.}=$ cerebral-buccal connective; $\mathrm{LBN}=$ laterobuccal nerve; $\mathrm{VBN}=$ ventrobuccal nerve. 
the esophagus. One OA-li fiber was sometimes detected in the cerebral-buccal connective (fig. $4 \mathrm{~A}_{3}$ ), but it was not possible to determine its origin.

\section{Octopamine Immunoreactive Neurons in the Buccal}

Ganglia of Helisoma

In Helisoma, three OA-li neurons were collectively designated neuron N3a [Quinlan and Murphy, 1996]. They are all morphologically and physiologically similar. Injection of all three N3a neurons in a single preparation with Lucifer yellow showed them to project to the contralateral hemiganglion, but no processes were seen to project to the periphery or to other ganglia (cf. fig. $4 \mathrm{~B}_{1}$ ). Dual staining of N3a neurons has also been observed in experiments combining dye injection with octopamine immunoreactivity (data not shown).

The N3a OA-li cells were found to act as the principal subunit 3 CPG interneurons of the Helisoma feeding CPG. During feeding motor programs, they fire primarily during the hyperretraction phase 3 [Quinlan and Murphy, 1996]. Their firing during hyperretraction is caused, in part by postinhibitory rebound following synaptic inhibition by the retraction phase CPG subunit 2 interneuron B2 [Quinlan et al., 1995]. The postinhibitory rebound of N3a is enhanced by serotonin. It is important to note that these neurons could be rhythmically active in the absence of inhibition from subunit 2 . They were shown to participate in phase 3-2 and 3-2-3 motor patterns, in addition to the standard 1-2-3 feeding motor pattern [Quinlan and Murphy, 1996]. Importantly, they excite the motor neurons that are primarily active during the hyperretraction phase of feeding and inhibit those that are inhibited during hyperretraction. Hyperpolarization of neurons N3a during feeding or during nonfeeding motor patterns reduces or eliminates phase 3 or phase 3-like activity in motor neurons.

\section{Discussion}

The data reviewed here underscore several related questions: (1) Does the buccal CPG of Aplysia include a third subunit that is active during the hyperretraction (swallowing) phase of feeding? (2) If such a subunit is present, to what extent does it provide the primary drive to the motor neurons active during hyperretraction? (3) Do the octopamine immunoreactive neurons of Aplysia, which are apparently homologous to Helisoma neurons $\mathrm{N} 3 \mathrm{a}$, serve as the hyperretraction subunit of the buccal CPG? (4) Do the SCP-li radula mechanoreceptors of Ap- lysia provide excitatory drive to the OA-li neurons? If so, (5) do the RM neurons of Aplysia influence the occurrence of CPG subunit 3 activity, as observed in Helisoma?

The movements of the radula-odontophore complex that occur during Aplysia feeding have been exceptionally well characterized [Weiss et al., 1986; Morton and Chiel, 1993a, b; Hurwitz, et al., 1996; Neustadter et al., 2007] and much is known about the neuromuscular and CPG elements that produce these actions [Susswein and Byrne, 1988; Plummer and Kirk, 1990; Church and Lloyd, 1994; Hurwitz and Susswein, 1996; Cropper et al., 2004]. In contrast to the Helisoma feeding motor programs, where the presence of a distinct third phase that produces hyperretraction of the radula/odontophore and facilitates swallowing is apparent [e.g. Quinlan and Murphy, 1996], the presence of an analogous phase 3 in Aplysia remains uncertain [see Cropper et al., 2004].

Interestingly, however, the observations reviewed here indicate that much of the circuitry that is responsible for phase 3 activity in Helisoma is also present in the Aplysia feeding system. It seems evident that the rostral cluster of SCP-li neurons in Aplysia is homologous to the Helisoma cluster. Each group is composed of radula mechanoreceptors with axons in equivalent nerves: Aplysia's radula nerve and Helisoma's posterior buccal nerves. One of the largest SCP-li neurons in each animal, Aplysia B21 and Helisoma $\mathrm{B} 102$, is also glutamatergic. Moreover, each set has central synaptic effects that are dependent upon the timing of activation within the motor pattern.

Although the physiological and functional properties of the OA-li interneurons of Aplysia are not known, their anatomical features suggest that they are also homologous to the N3a cells of Helisoma. These anatomical features also invite comparison to a set of three well-studied OA-li neurons (termed OCs) in the feeding motor system of Lymnaea stagnalis [Elliott and Vehovszky, 2000; Vehovszky and Elliott, 2000, 2001; Vehovszky et al., 2000, 2004]. The OCs are widely-acting buccal interneurons that fire during the swallowing phase of feeding motor programs [Vehovszky and Elliott, 2001]. OC synaptic actions influence follower neurons over a range of temporal intervals and can activate and reconfigure motor programs [Vehovszky et al., 1998, 2004, 2005]. They were therefore proposed to act as intrinsic modulators of the Lymnaea feeding CPG, rather than sensu stricto CPG participants [Vehovszky and Elliott, 2001, 2002]. Although the modulatory actions of the OA neurons are well documented [e.g. Vehovszky and Elliott, 2002; Vehovszky et al., 2004], their direct excitation of motor neu- 
Fig. 5. Schematic summary of proposed actions of OA-li and SCPli neurons. This diagram is simplified to emphasize the roles of the neurons considered in this article. The polymorphic feeding motor systems of Helisoma and Aplysia can generate many variants of the feeding sequences depicted. Upper panel: during a bite without food contact, SCP-li RMs (B101 cluster neurons of Helisoma and RM cells of Aplysia) receive minimal exteroceptive stimulation. Under these conditions, OA interneuron firing (smaller font) does not evoke maximal hyperretraction in Helisoma and may not occur in Aplysia. In this sequence of actions, referred to as 'biting' in Aplysia [see Cropper et al., 2004], closure of the radula, which can be initiated by several pathways [see e.g. Plummer and Kirk, 1990; Evans and Cropper, 1998; Jing et al., 2004], begins near the peak of protraction and is primarily associated with the retraction phase. Lower panel: when a bite does encounter food or exteroceptive resistance, the SCP mechanoafferents are activated during the late phase of protraction. In Heliso$m a$, they act in an 'influential' fashion on the OA-li interneurons (dashed curved arrow), increasing the intensity and duration of their firing (bold text, compare to upper panel). In Helisoma, this causes a stronger and more prolonged hyperretraction phase. We propose that the RM cells of Aplysia will similarly promote strong activation of the OA-li neurons and enhanced hyperretraction movements. The well characterized direct actions of the Aplysia RM neurons on radula closer motor neurons [Rosen et al., 2000a; Shetreat-Klein and Cropper, 2004] will contribute to coordinating radula closure with the prolongation of radula retraction.

rons that fire prominently during 'swallowing' (e.g. B4) would appear to support their inclusion in the CPG [see also review of Chase, 2002] and their functional homology to the N3a neurons of Helisoma. Part of the hesitancy to consider the Lymnaea OCs as CPG phase 3 interneurons might be attributable to the fact that CPG organization is plastic and subunit 3 activity does not obligatorily occur only after phase 2 [see Quinlan and Murphy, 1996; Murphy, 2001].

\section{Functional Considerations}

The comparison of molluscan feeding circuits performed here emphasizes commonalities in certain sets of neurons that influence circuit output, i.e., the parameter upon which evolution acts [Dumont and Robertson, 1986; Arbas et al., 1991]. A notable difference between present models of the feeding CPGs of Helisoma and Aplysia reflects the readiness with which a third hyperretraction phase can be observed occurring in their motor programs. We propose that insight into this difference can be disclosed via further study of the neurons examined here.

In the rasper Helisoma, the RM neurons appear to act chiefly to compensate for load increases as the odonto-

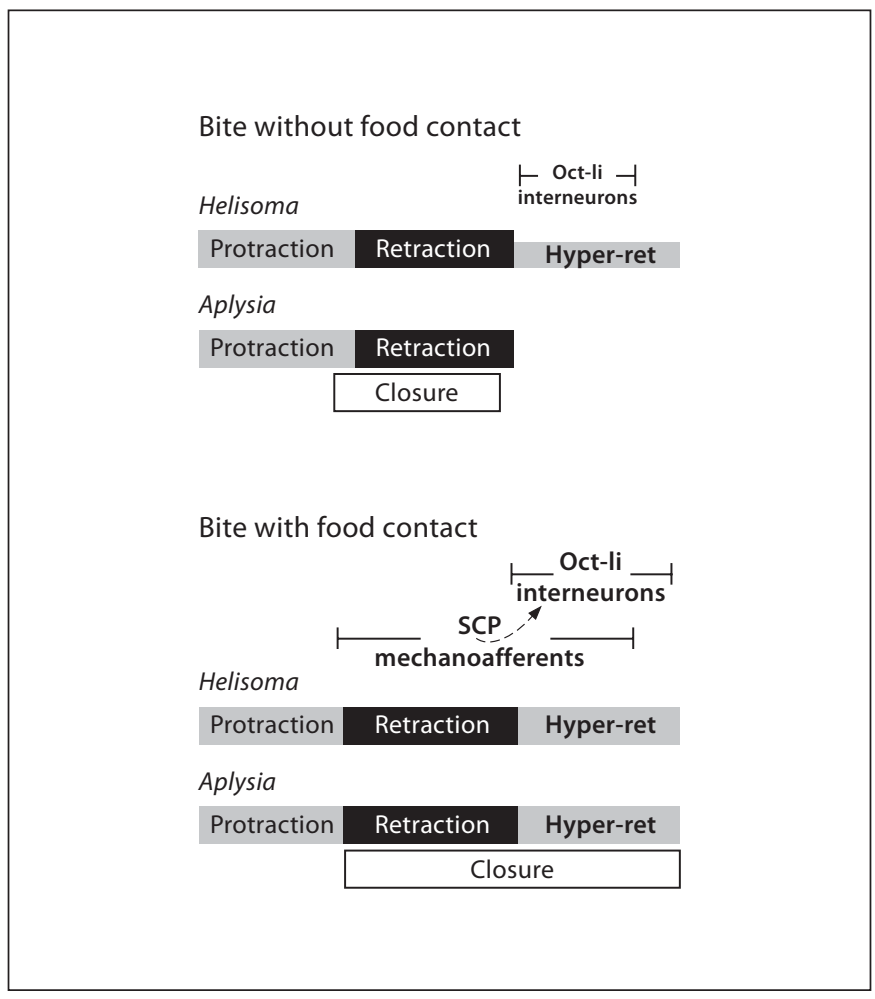

phore is swept across harder or more adhesive substrata (fig. 5). This compensation will promote more powerful activation of those muscles such as the slrt muscle (A. I4) and the anterior jugalis (A. I3) that normally provide the intense pull on the odontophore to hyperretract it to the opening of the esophagus. Functionally, the most prominent role of the SCP-li RM neurons in Helisoma is their 'influential' control over the synaptic excitation that drives hyperretraction phase motor neurons. This influence is thought to derive from electrotonic coupling with the octopaminergic N3a neurons. Although this coupling has not been directly documented due to the unfavorable locations of B101 (rostral surface) and N3a (caudal surface) for simultaneous recording, both neurons are known to be electrically coupled to the hyperretraction phase motor neuron B19.

In A. californica, fictive 'swallowing' corresponds to a prolongation of the retraction phase, also referred to as hyperretraction, during which both retraction and closure are enhanced and prolonged [cf. Weiss et al., 1986; Cropper et al., 1990; Evans and Cropper, 1998; Jing et al., 2004]. The timing of RM neuron firing (fig. 2) and their direct synaptic connections to radula closer/retraction motor neurons suggest their functional role in stabilizing 
closure of the radula as it retracts during ingestion of the stick-like algae serving as food. The direct excitatory signaling from B21 to the radula closer motor neuron B8 has been analyzed in great detail [Klein et al., 2000; Rosen et al., 2000a; Evans et al., 2003a, b, 2005, 2007, 2008], and depolarization of a single RM cell has been shown to be capable of prolonging the closure/retraction phase of carbachol-induced ingestive motor programs [ShetreatKlein and Cropper, 2004].

There is thus strong evidence for the participation of the RM cells in a direct sensory-to-motor neuron pathway that conjointly prolongs both radula retraction and closure in Aplysia [see 'Discussion' of Shetreat-Klein and Cropper, 2004]. Such a mechanism, coupled with the fact that distinct transitions from retraction to hyperretraction are rarely noted in motor neuron firing patterns would appear to circumvent the need for a dedicated hyperretraction CPG controller or module. By comparing the activity of an unidentified buccal motor neuron with that of the retraction phase neuron B4/5, however, Murphy [2001] proposed that such a phase transition could in fact be discriminated (see fig. 3). Moreover, detailed examination and quantification of B8 neuron activity during fictive swallowing motor programs enabled Jing and coworkers [2004] to clearly resolve a phase of hyperretraction. We hypothesize that the OA-li neurons near/in the commissure of Aplysia, in keeping with their apparent role in the grazing pulmonates, act as hyperretraction phase interneurons in the Aplysia feeding CPG (fig. 5).

Bullock [2002] advised against dwelling upon commonalities and homologies that can distract comparative studies from the primary role of evolution - i.e. to create differences. Thus, although our central hypothesis emphasizes conserved circuit elements within the core gastropod CPG, major differences in the neural control of feeding in Aplysia with respect to that of the basommatophoran snails involve the control of radula closure and its plasticity of timing with respect to the phases of protraction, retraction and hyperretraction.

Regulation of radula closure, which does not occur in the rasping snails, appears to involve significant differences in the innervation of possibly homologous muscles, Aplysia I4 and Helisoma slrt. Whereas the I4 muscle of Aplysia receives major innervation from $\mathrm{B} 8$ via the radular nerve (= the posterior buccal nerves of Helisoma), the slrt of Helisoma is innervated by a number of large motor neurons, e.g., B18, B19, B110, via the ventrobuccal nerve (= BN3 of Aplysia). If the innervation of I4 by neuron B8 is a derived condition associated with radula closure, it raises the interesting and testable hypothesis that herbiv- orous opisthobranchs with non-closing radulae might have an innervation pattern of muscles analogous, possibly homologous to Aplysia I4 that is more like the innervation pattern of Helisoma slrt muscles. Cephalaspids such as Bulla and Haminoea that feed primarily on diatoms and filamentous algae [Malaquias et al., 2009] could present opportunities to test this hypothesis. If muscle innervation patterns can shift so readily as a function of feeding mode and ecological niche, a number of interesting correlates could emerge. For instance, it would be more difficult to ascribe directionality to changes in muscle innervation patterns. It might also imply that homologies in neuromuscular systems might be difficult to establish at the level of motor neurons.

In addition to the Aplysia, Helisoma and Lymnaea systems discussed here, aspects of the neuronal control of feeding have been investigated in a wide range of pulmonate and opisthobranch mollusks. A sample would include Planorbis [Arshavsky et al., 1988], Limax [Gelperin et al., 1978], Helix [Peters and Altrup, 1984], Achatina [Yoshida and Kobayashi, 1992], Navanax [Cappell et al., 1989], Tritonia [Bulloch and Dorsett, 1979], Pleurobranchaea [Gillette and Gillette, 1983], and Clione [Moroz et al., 2000]. Each of these feeding motor systems contains many uniquely identifiable neurons. Possible homologous neurons are readily apparent in closely related species and still discernible in distantly related species. There has been a vast radiation of ecological niches and divergence of gastropod feeding strategies, especially among the opisthobranchs. Thus, these species provide ample opportunities, not only for examining neuronal homologies, but also for studies of evolutionary divergence. Clearly, our understanding of each of these systems will be enriched by comparing the findings in one with those of the others.

\section{Acknowledgments}

Supported by the National Institutes of Health: RCMI RR03051, NIGMS MBRS: GM-087200 and GM-061838; National Science Foundation DBI-0115825; BNS-9121374; IBN-9728769.

References

\footnotetext{
Alexeeva V, Borovikov D, Miller MW, Rosen SC, Cropper EC (1998) Effect of a serotonergic extrinsic modulatory neuron (MCC) on radula mechanoafferent function in Aplysia. J Neurophysiol 80:1609-1622.

-Arbas EA, Meinertzhagen IA, Shaw SR (1991) Evolution in nervous systems. Annu Rev Neurosci 14:9-38.
} 
Arnett BC (1996) Feeding and regurgitation: two modes of operation of the buccal central pattern generator in Helisoma. $\mathrm{PhD}$ thesis, Chicago, IL: University of Illinois at Chicago.

-Arshavsky YI, Deliagina TG, Meizerov ES, Orlovsky GN, Panchin YV (1988) Control of feeding movements in the freshwater snail, Planorbis corneus. I. Rhythmic neurons of buccal ganglia. Exp Brain Res 70:310-322.

Audesirk T, Audesirk G (1985) Behavior of gastropod mollusks. In: The Mollusca. Neurobiology and Behavior, Part 1, Vol. 8 (Willows AOD, ed), pp 2-94. Orlando, FL: Academic Press.

Benjamin PR (1983) Gastropod Feeding: behavioural and neural analysis of a complex multicomponent system. In: Neural Origin of Rhythmic Movements (Roberts A, Roberts BL, eds), pp 159-193. Cambridge, UK: Cambridge University Press.

Borovikov D, Evans CG, Jing J, Rosen SC, Cropper EC (2000) A proprioceptive role for an exteroceptive mechanoafferent neuron in Aplysia. J Neurosci 20:1990-2002.

- Bulloch AGM, Dorsett DA (1979) The functional morphology and motor innervation of the buccal mass of Tritonia hombergi. J Exp Biol 79:7-22.

Bulloch AGM, Ridgeway RL (1995) Comparative aspects of gastropod neurobiology. In: The Nervous Systems of Invertebrates: An Evolutionary and Comparative Approach (Breidback O, Kutsch W, eds), pp 89-113. Boston, MA: Birkhauser Verlag.

- Bullock TH (2002) Grades in neural complexity: how large is the span? Integr Comp Biol 42: 757-776.

Bullock TH, Horridge GA (1965) Structure and Function in the Nervous Systems of Invertebrates. 2 vols. San Francisco and London: WH Freeman and Co.

Camhi JM (1984) Neuroethology: Nerve Cells and the Natural Behavior of Animals. Sunderland, MA: Sinauer.

-Cappell MS, Spray DC, Susswein AJ, Bennett MV (1989) Neuronal analysis of pharyngeal peristalsis in the gastropod Navanax in terms of identified motoneurons innervating identified muscle bands. II. Radial and circumferential motor fields. Brain Res 502: 266-279.

Chase R (2002) Behavior and its Neural Control in Gastropod Mollusks. New York: Oxford University Press.

-Church PJ, Lloyd PE (1991) Expression of diverse neuropeptide cotransmitters by identified motor neurons in Aplysia. J Neurosci 11:618625.

- Church PJ, Lloyd PE (1994) Activity of multiple identified motor neurons recorded intracellularly during evoked feedinglike motor programs in Aplysia. J Neurophysiol 72:17941809.

Croll RP (1987) Identified neurons and cellular homologies. In: Nervous Systems in Invertebrates (Ali MA, ed), pp 41-59. New York: Plenum Press.
Cropper EC, Kupfermann I, Weiss KR (1990) Differential firing patterns of the peptidecontaining cholinergic motor neurons B15 and B16 during feeding behavior in Aplysia. Brain Res 522:176-179.

Cropper EC, Evans CG, Rosen SC (1996) Multiple mechanisms for peripheral activation of the peptide-containing radula mechanoafferent neurons B21 and B22 in Aplysia. J Neurophysiol 76:1344-1351.

Cropper EC, Evans CG, Hurwitz I, Proekt A, Romero A, Rosen SC (2004) Feeding neural networks in the mollusc Aplysia. Neurosignals 13:70-86.

Delfeld MM (2008) Myriad effects of radular mechanosensation on a feeding central pattern generator in Helisoma. $\mathrm{PhD}$ thesis, Chicago, IL: University of Illinois at Chicago.

Dethier VG, Stellar E (1961) Animal Behavior: Its Evolutionary and Neurological Basis. Englewood Cliffs, NJ: Prentice Hall, Inc.

Duda TF Jr, Kohn AJ, Palumbi SR (2001) Origins of diverse feeding ecologies within Conus, a genus of venomous marine gastropods. Biol J Linnean Soc 73:391-409.

Dumont JP, Robertson RM (1986) Neuronal circuits: an evolutionary perspective. Science 233:849-853.

Elliott CJ, Susswein AJ (2002) Comparative neuroethology of feeding control in molluscs. J Exp Biol 205:877-896.

-Elliott CJH, Vehovszky A (2000) Polycyclic neuromodulation of the feeding rhythm of the pond snail Lymnaea stagnalis by the intrinsic octopaminergic interneuron, OC. Brain Res 887:63-69.

Evans CG, Cropper EC (1998) Proprioceptive input to feeding motor neurons in Aplysia. J Neurosci 18:8016-8031.

Evans CG, Jing J, Proekt A, Rosen SC, Cropper EC (2003a) Frequency-dependent regulation of afferent transmission in the feeding circuitry of Aplysia. J Neurophysiol 90:39673877.

Evans CG, Jing J, Rosen SC, Cropper EC (2003b) Regulation of spike initiation and propagation in Aplysia sensory neuron: gating-in via central depolarization. J Neurosci 23:29202931.

Evans CG, Romero A, Cropper EC (2005) Inhibition of afferent transmission in the feeding circuitry of Aplysia: persistence can be as important as size. J Neurophysiol 93:29402949.

-Evans CG, Ludwar BCh, Cropper EC (2007) Mechanoafferent neuron with an inexcitable somatic region: consequences for the regulation of spike propagation and afferent transmission. J Neurophysiol 97:3126-3130.

Evans CG, Kang T, Cropper EC (2008) Selective spike propagation in the central processes of an invertebrate neuron. J Neurophysiol 100: 2940-2947.

Gelperin A, Chang JJ, Reingold SC (1978) Feeding motor program in Limax. I. Neuromuscular correlates and control by chemosensory input. J Neurobiol 9:285-300.
Gillette MU, Gillette R (1983) Bursting neurons command consummatory feeding behavior and coordinated visceral receptivity in the predatory mollusk Pleurobranchaea. J Neurosci 3:1791-1806.

Granzow B, Rowell CHF (1981) Further observations on the serotonergic cerebral neurons of Helisoma (Mollusca, Gastropoda): the case for homology with the metacerebral giant cells. J Exp Biol 90:283-305.

Hurwitz I, Susswein AJ (1996) B64, a newly identified central pattern generator element producing a phase switch from protraction to retraction in buccal motor programs of $A p$ lysia californica. J Neurophysiol 75:13271344.

Hurwitz I, Neustadter D, Morton DW, Chiel HJ, Susswein AJ (1996) Activity patterns of the B31/B32 pattern initiators innervating the I2 muscle of the buccal mass during normal feeding movements in Aplysia californica. J Neurophysiol 75:1309-1326.

-Jing J, Cropper EC, Hurwitz I, Weiss KR (2004) The construction of movement with behavior-specific and behavior-independent modules. J Neurosci 24:6315-6325.

Kandel ER (1975) Cellular Basis of Behavior: An Introduction to Behavioral Neurobiology. San Francisco, CA: WH Freeman and Co.

Kandel ER (1979) Behavioral Biology of Aplysia. San Francisco, CA: WH Freeman and Co.

Kater SB (1974) Feeding in Helisoma trivolvis: the morphological and physiological bases of a fixed action pattern. Am Zool 14:10171036.

Katz PS (1991) Neuromodulation and the evolution of a simple motor system. Sem Neurosci 3:379-389.

Katz PS, Harris-Warrick RM (1999) The evolution of neuronal circuits underlying speciesspecific behavior. Curr Opin Neurobiol 9: 628-633.

Klein AN, Weiss KR, Cropper EC (2000) Glutamate is the fast excitatory transmitter of small cardioactive peptide-containing Aplysia radula mechanoafferent neuron B21. Neurosci Lett 289:37-40.

Kohn AJ (1983) Feeding biology of gastropods. In: The Mollusca, Vol 5, part 2 (Saleuddin ASM, Wilbur KM, eds), pp 1-63. New York: Academic Press.

Kupfermann I (1974a) Feeding behavior in Aplysia: a simple system for the study of motivation. Behav Biol 10:1-26.

Kupfermann I (1974b) Dissociation of the appetitive and consummatory phases of feeding behavior in Aplysia: a lesion study. Behav Biol 10:89-97.

- Lloyd PE, Frankfurt M, Stevens P, Kupfermann I, Weiss KR (1987) Biochemical and immunocytological localization of the neuropeptides FMRFamide, $\mathrm{SCP}_{\mathrm{A}}, \mathrm{SCP}_{\mathrm{B}}$, to neurons involved in the regulation of feeding Aplysia. J Neurosci 7:1123-1132. 
Lorenz K (1950) The comparative method in studying innate behaviour patterns. In: Soc Exp Biol Symp on Physiological Mechanisms in Animal Behaviour, pp 221-268. New York: Academic Press.

Lukowiak K, Murphy AD (1987) Molluscan model systems for the study of neuropeptides. In: Neuromethods, Vol. 6: Peptides (Boulton, AA, Baker GB, Pittman QJ, eds), pp 439-476. Clifton, NJ: The Humana Press Inc.

- Malaquias MAE, Berecibar E, Reid DG (2009) Reassessment of the trophic position of Bullidae (Gastropoda: Cephalaspidea) and the importance of diet in the evolution of cephalaspidean gastropods. J Zool 277:88-97.

Martínez-Rubio C, Serrano GE, Miller MW (2008) Immunohistochemical localization and modulatory actions of octopamine in the feeding network of Aplysia californica. Program no. 574.17. Neuroscience Meeting Planner. Washington, DC: Society for Neuroscience, 2008. Online.

-Masinovsky B, Kempf SC, Callaway JC, Willows AO (1988) Monoclonal antibodies to the molluscan small cardioactive peptide SCPB: immunolabeling of neurons in diverse invertebrates. J Comp Neurol 273:500-512.

Mason WA, Lott DF (1976) Ethology and comparative psychology. Annu Rev Psychol 27: 129-154.

- Miller MW, Rosen SC, Schissel SL, Cropper EC, Kupfermann I, Weiss KR (1994) A population of SCP-containing neurons in the buccal ganglion of Aplysia are radula mechanoafferents and receive excitation of central origin. J Neurosci 14:7008-7023.

Moroz LL, Norekian TP, Pirtle TJ, Robertson KJ, Satterlie RA (2000) Distribution of NADPHdiaphorase reactivity and effects of nitric oxide on feeding and locomotory circuitry in the pteropod mollusc, Clione limacina. J Comp Neurol 427:274-284.

-Morton DW, Chiel HJ (1993a) In vivo buccal nerve activity that distinguishes ingestion from rejection can be used to predict behavioral transitions in Aplysia. J Comp Physiol A $172: 17-32$.

Morton DW, Chiel HJ (1993b) The timing of activity in motor neurons that produce radula movements distinguishes ingestion from rejection in Aplysia. J Comp Physiol A 173: 519-536.

Murphy AD (2001) The neuronal basis of feeding in the snail, Helisoma, with comparisons to selected gastropods. Prog Neurobiol 63 383-408.

Murphy AD, Lukowiak K, Stell WK (1985) Peptidergic modulation of patterned motor activity in identified neurons of Helisoma. Proc Natl Acad Sci USA 82:7140-7144.

- Neustadter DM, Herman RL, Drushel RF, Chestek DW, Chiel HJ (2007) The kinematics of multifunctionality: comparisons of biting and swallowing in Aplysia californica. J Exp Biol 210:238-260.
Paul DH (1991) Pedigrees of neurobehavioral circuits: tracing the evolution of novel behaviors by comparing motor patterns, muscles, and neurons in members of related taxa. Brain Behav Evol 38:226-239.

Pentreath VW, Berry MS, Osborne NN (1982) The serotonergic cerebral cells in gastropods. In: Biology of Serotonergic Transmission (Osborne NN, ed), pp 457-513. Chichester, UK: John Wiley \& Sons.

Peters M, Altrup U (1984) Motor organization in pharynx of Helix pomatia. J Neurophysiol 52:389-409.

Plummer MR, Kirk MD (1990) Premotor neurons B51 and B52 in the buccal ganglia of Aplysia californica: synaptic connections, effects on ongoing motor rhythms, and peptide modulation. J Neurophysiol 63:539-558.

-Quinlan EM, Gregory K, Murphy AD (1995) An identified glutamatergic interneuron patterns feeding motor activity via both excitation and inhibition. J Neurophysiol. 73:945956.

Quinlan EM, Murphy AD (1996) Plasticity in the multifunctional buccal central pattern generator of Helisoma illuminated by the identification of phase 3 interneurons. J Neurophysiol 75:561-574.

Rose RM, Benjamin PR (1981) Interneuronal control of feeding in the pond snail Lymnaea stagnalis. II. The interneuronal mechanisms generating feeding cycles. J Exp Biol 92:203228.

Rosen SC, Miller MW, Evans CG, Cropper EC, Kupfermann I (2000a) Diverse synaptic connections between peptidergic radula mechanoafferent neurons and neurons in the feeding system of Aplysia. J Neurophysiol 83: 1605-1620.

Rosen SC, Miller MW, Cropper EC, Kupfermann I. (2000b) Outputs of radula mechanoafferent neurons in Aplysia are modulated by motor neurons, interneurons, and sensory neurons. J Neurophysiol 83:1621-1636.

Sakharov DA (1976) Nerve cell homologies in gastropods. In: Neurobiology of Invertebrates: Gastropoda Brain (Salánki J, ed), pp 27-39. Budapest: Akad Kiado.

- Schneirla TC (1952) A consideration of some conceptual trends in comparative psychology. Psychol Bull 49:559-597.

-Shetreat-Klein AN, Cropper EC (2004) Afferentinduced changes in rhythmic motor programs in the feeding circuitry of Aplysia. J Neurophysiol 92:2312-2322.

-Susswein AJ, Achituv Y, Cappell MS, Bennett MVL (1987) Pharyngeal movements during feeding sequences of Navanax inermis (Gastropoda: Opisthobranchia) in successive stages of dissection. J Exp Biol 128:323333.

Susswein AJ, Byrne JH (1988) Identification and characterization of neurons initiating patterned neural activity in the buccal ganglia of Aplysia. J Neurosci 8:2049-2061.
Szabo TM (2001) Regulatory mechanisms governing electrical synaptogenesis during regeneration of neural networks. PhD Thesis. College Station, TX: Texas A\&M University.

-Vehovszky A, Elliott CJH (2000) The octopamine-containing buccal neurons are a new group of feeding interneurons in the pond snail Lymnaea stagnalis. Acta Biol Hung 51: 165-176.

-Vehovszky A, Elliott CJH (2001) Activation and reconfiguration of fictive feeding by the octopamine-containing modulatory OC interneurons in the snail Lymnaea. J Neurophysiol 86:792-208.

-Vehovszky A, Elliott CJH (2002) Heterosynaptic modulation by the octopaminergic OC interneurons increases the synaptic outputs of protraction phase interneurons $(\mathrm{SO}, \mathrm{N} 1 \mathrm{~L})$ in the feeding system of Lymnaea stagnalis. Neuroscience 115:483-494.

-Vehovszky A, Elliott CJH, Voronezhskaya EE, Hiripi L, Elekes K (1998) Octopamine: a new feeding modulator in Lymnaea. Phil Trans R Soc Lond B 353:1631-1643.

-Vehovszky A, Hiripi L, Elliott CJH (2000) Octopamine is the synaptic transmitter between identified neurons in the buccal feeding network of the pond snail Lymnaea stagnalis. Brain Res 867:188-199.

Vehovszky A, Szabó H, Elliott CJH (2004) Octopamine-containing (OC) interneurons enhance central pattern generator activity in sucrose-induced feeding in the snail Lymnaea. J Comp Physiol A Neuroethol Sens Neural Behav Physiol 190:837-846.

-Vehovszky A, Szabó H, Elliott CJH (2005) Octopamine increases the excitability of neurons in the snail feeding system by modulation of inward sodium current but not outward potassium currents. BMC Neuroscience 6:70.

Weiss KR, Kupfermann I (1976) Homology of the giant serotonergic neurons (metacerebral cells) in Aplysia and pulmonate mollusks. Brain Res 117:33-49.

-Weiss KR, Chiel HJ, Koch U, Kupfermann I (1986) Activity of an identified histaminergic neuron, and its possible role in arousal of feeding behavior in semi-intact Aplysia. J Neurosci 6:2403-2415.

-Wiersma CAG (1952) Neurons of arthropods. Cold Spring Harbor Symp Quant Biol 17: 155-163.

Willows AOD, Hoyle G (1967) Correlation of behavior with the activity of single identifiable neurons in the brain of Tritonia. In: Neurobiology of Invertebrates (Salánki J, ed), pp 443-461. New York: Plenum Press.

Yoshida M, Kobayashi M (1992) Cerebral and buccal neurons involved in buccal motor pattern generation in Achatina fulica. Acta Biol Hung 43:361-366.

Zoran MJ, Haydon PG, Matthews PJ (1989) Aminergic and peptidergic modulation of motor function at an identified neuromuscular junction in Helisoma. J Exp Biol 142: 225-243. 